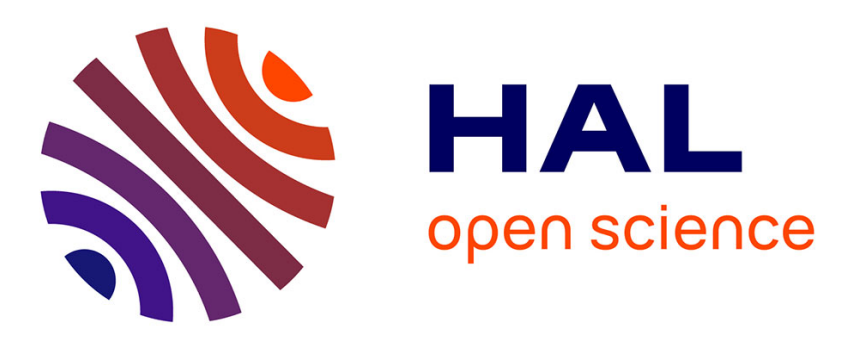

\title{
Study of required conditions to limit the dielectric charging phenomenon when measuring the electron emission yield from thin dielectric layers
}

Charles Rigoudy, Kremena Makasheva, G. Teyssedre, Laurent Boudou, M. Belhaj, S. Dadouch

\section{To cite this version:}

Charles Rigoudy, Kremena Makasheva, G. Teyssedre, Laurent Boudou, M. Belhaj, et al.. Study of required conditions to limit the dielectric charging phenomenon when measuring the electron emission yield from thin dielectric layers. 2018 IEEE 2nd International Conference on Dielectrics (ICD), Jul 2018, Budapest, Hungary. pp.1-4, 10.1109/ICD.2018.8468360 . hal-02324382

\section{HAL Id: hal-02324382 \\ https://hal.science/hal-02324382}

Submitted on 1 Nov 2019

HAL is a multi-disciplinary open access archive for the deposit and dissemination of scientific research documents, whether they are published or not. The documents may come from teaching and research institutions in France or abroad, or from public or private research centers.
L'archive ouverte pluridisciplinaire HAL, est destinée au dépôt et à la diffusion de documents scientifiques de niveau recherche, publiés ou non, émanant des établissements d'enseignement et de recherche français ou étrangers, des laboratoires publics ou privés. 


\section{Study of required conditions to limit the dielectric charging phenomenon when measuring the electron emission yield from thin dielectric layers}

\author{
C. Rigoudy ${ }^{1,2, *}$, K. Makasheva ${ }^{1}$, G. Teyssedre ${ }^{1}$, \\ L. Boudou ${ }^{1}$ \\ LAPLACE, Université de \\ Toulouse, CNRS,
}

118 route de Narbonne Toulouse Cedex 9, 31062 France

\author{
M. Belhaj ${ }^{2}$, S. Dadouch ${ }^{2}$ \\ ONERA - The French Aerospace Lab, \\ FR-31062 Toulouse Cedex 4
}

*charles.rigoudy@laplace.univ-tlse.fr

\begin{abstract}
The electron emission yield of materials is an important quantity to be determined in various fields of physics. Among them, dielectric materials have a strong ability to retain charges and remain charged when submitted to electrical field, in particular when irradiated by electron beam. Without the use of specific measurement methodology, experimental investigation of dielectric materials may lead to an inaccurate measurement of the total electron emission yield (TEEY). This paper shows that a particular attention should be paid to the pulse duration of the incident electron beam and to hysteresis effects induced by charge trapping.
\end{abstract}

Keywords—dielectric charging, thin layers, electron emission

\section{INTRODUCTION}

Many areas of fundamental physics and technological devices such as scanning electron microscopy (SEM) [1], plasma physics [2], space applications [3, 4], particle accelerator [5], etc., are based on or concerned by the electron emission (EE) phenomenon. The electron emission is a mechanism of release of electrons from materials under energetic particles (electrons, ions, atoms, photons) impact. The most needed parameter that quantifies the EE mechanism is the total electron emission yield (TEEY). TEEY, is the ratio of the total number of emitted electrons (secondary and backscattered) to the number of incident electrons. In contrast to metals the measurements of TEEY on dielectrics require consideration of dielectric charging effects. Indeed dielectric charging during irradiation interferes with the incident electrons and affects the TEEY itself [6]. A comprehensive review based on theoretical considerations of the effect of dielectric charging on the TEEY was given by Cazaux [7, 8].

When measuring the TEEY on metals one can use a continuous electrons beam, because the emission of secondary electrons does not affect the conductive properties of the material under study. There are enough free electrons in the conduction band of the probed metal so the extraction of an electron does not lead to a positive charge build-up (Fig. 1.a) or other side effects. Based on that mechanism the measured values of TEEY for metals are typically less than 2 as reported

*Research supported by the program IDEX Actions Thématiques Stratégiques - ATS 2015 of the Université de Toulouse under project SEPHIR (2016-066-CIF-D-DRVD). C. Rigoudy acknowledges PhD grant from the Université de Toulouse. in the literature [9].

The TEEY universal curve is shown in Fig. 2. It increases when increasing the energy of the incident electrons up to a maximum value, followed by a decrease for higher energies and is characterized by two crossover energies $\left(\mathrm{E}_{\mathrm{C} 1}\right.$ and $\left.\mathrm{E}_{\mathrm{C} 2}\right)$. The TEEY is lower than 1 when $\mathrm{E}<\mathrm{E}_{\mathrm{C} 1}$ and $\mathrm{E}>\mathrm{E}_{\mathrm{C} 2}$ and higher than 1 for $\mathrm{E}_{\mathrm{C} 1}<\mathrm{E}<\mathrm{E}_{\mathrm{C} 2}$.

Based on the nature of dielectric materials the above description should be revised. The energy diagram of a dielectric material consists of valence and conduction bands well separated by the energy gap (Fig. 1.b). Depending on the dielectric material the energy gap is different; for example it is of $9.0 \mathrm{eV}$ for stoichiometric $\mathrm{SiO}_{2}, 7.5 \mathrm{eV}$ for the $\mathrm{Si}_{3} \mathrm{~N}_{4}, 3.5 \mathrm{eV}$ for the $\mathrm{TiO}_{2}$, etc. [10]. In reality, the energy gap of dielectrics is reduced by the energy corresponding to the band tails, situated close to the valence and the conduction bands and by the presence of possible localized states (Fig. 1.b). This determines the main differences observed in the TEEY measurements from dielectrics. The TEEY curve from dielectrics follows the same trends as the one from metals but the measured TEEY

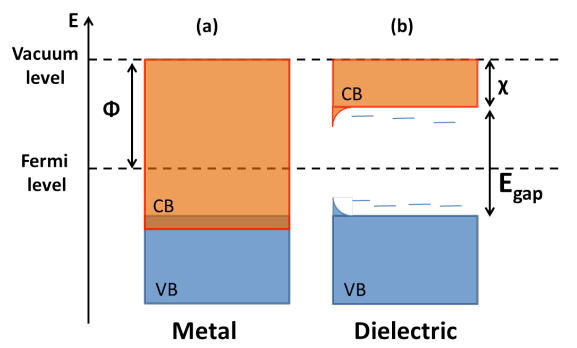

Fig. 1. Energy diagram: (a) metals, (b) dielectrics. VB stand for valence band; CB for conduction band.

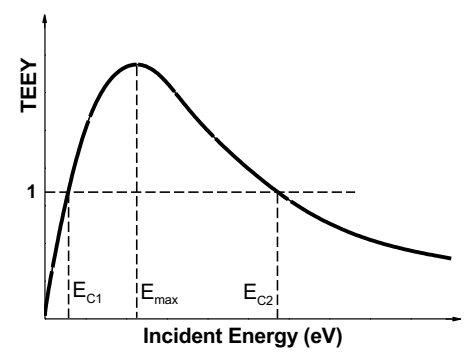

Fig. 2. TEEY universal curve. Between crossover energies $E_{\mathrm{C} 1}$ and $E_{\mathrm{C} 2}$ more than 1 electron is emitted for an incident electron: a dielectric charges positively. 
values are higher than one for a large range of the energy of incident electrons. Between the cross-over points $\mathrm{E}_{\mathrm{C} 1}$ and $\mathrm{E}_{\mathrm{C} 2}$, where the TEEY is higher than one the dielectric is positively charged because the extraction of an electron from it provides an uncompensated charge. Thus in the case of dielectric material, every previous measurement will affect the following ones.

In this work we focus on the way to limit the dielectric charging phenomenon during measurements of TEEY. It is intended to reveal the influence of the dielectric charging on the interpretation of the obtained TEEY measurements. To that end we use thin thermal $\mathrm{SiO}_{2}$ layers to increase the capacitance of the $\mathrm{SiO}_{2} / \mathrm{Si}$ system and therefore to limit the induced surface potential [7].

\section{SAMPLES ELABORATION}

Silicon wafers (intrinsic or with low doping level, resistivity $\rho=7$ to $13 \Omega . \mathrm{cm}$, type $\mathrm{n}$ ) purchased from Sil'tronix were used. Before being oxidized they were chemically cleaned using Piranha solution (mixture of hydrogen peroxide $\left(\mathrm{H}_{2} \mathrm{O}_{2}\right)$ and sulfuric acid $\left.\left(\mathrm{H}_{2} \mathrm{SO}_{4}\right)\right)$ and then rinsed in deionized water. The native oxide was removed by chemical etching in hydrofluoric acid (HF). Each step was followed by rinsing in deionized water.

The Si-wafers were oxidized at $1100^{\circ} \mathrm{C}$ under controlled atmosphere in a mixture of $\mathrm{N}_{2}$ containing $1 \% \mathrm{O}_{2}$, at a pressure of $1 \mathrm{~atm}$. The above described oxidation process results in stoichiometric $\mathrm{SiO}_{2}$ layers with thickness of around $120 \mathrm{~nm}$. In order to study $\mathrm{SiO}_{2}$-layers with specific thicknesses the thickness of the so-elaborated thermal $\mathrm{SiO}_{2}$-layers was reduced by chemical etching in HF followed by rinsing in deionized water. The samples were rinsed until measuring zero surface conductivity. The etching rate was constant $\left(12 \mathrm{~nm} \cdot \mathrm{min}^{-1}\right)$ so the targeted thickness can be reached quite precisely. Finally, the studied $\mathrm{SiO}_{2}$ thin layers were in the sub-100 $\mathrm{nm}$ thickness range.

\section{ChARACTERIZATION METHODS}

\section{A. Thickness measurement}

The thicknesses of $\mathrm{SiO}_{2}$ layers were determined by spectroscopic ellipsometry using a SOPRA GES-5 ellipsometer in the range $250-850 \mathrm{~nm}$. The recorded spectra were proceeded by using Bruggeman's model [11]. In order to verify the homogeneity of the oxide layer thickness a mapping was performed. Ellipsometry spectra were recorded on 37 points arranged in polar coordinates with a step of $7 \mathrm{~mm}$ in radius and an angle $\Theta=30^{\circ}$, resulting in more measurements near the central zone. Further characterization measurements (structural and those related to the TEEY), were performed in the central zone of the samples.

\section{B. Structural characterization}

The thermal $\mathrm{SiO}_{2}$ layers were further structurally characterized by Fourier Transform Infrared (FTIR) spectroscopy. The FTIR measurements were performed using a VERTEX70 apparatus in transmission mode. The transmission method can be applied to intrinsic $\mathrm{Si}$ substrates due to transparency of intrinsic $\mathrm{Si}$ to infrared light. The used wavelength range was from $400 \mathrm{~cm}^{-1}$ to $4000 \mathrm{~cm}^{-1}$ with a resolution of $2 \mathrm{~cm}^{-1}$.

\section{Total electron emission yield}

The TEEY was measured in an experimental facility specially designed for electron emission characterization [12]. The measurements were realized under high vacuum $\left(5 \times 10^{-6}\right.$ $\mathrm{Pa})$. The electron irradiation was performed using a low energy electron gun (Kimball Physics ELG-2) in the range from $1 \mathrm{eV}$ to $2 \mathrm{keV}$.

Considering $I_{0}$ the incident current (incident electrons), $I_{E}$ the current represented by the emitted electrons, and $I_{S}$ the current that flows between the sample and the ground (sample current), the current conservation law reads:

$$
I_{0}=I_{E}+I_{S}
$$

\section{Each TEEY measurement was performed in two steps:}

1) the sample holder was polarized at $+27 \mathrm{~V}$. Thus the low energy emitted secondary electrons are retracted back to the surface. The measured $I_{S}$ in this situation is very close to $I_{0}$ for materials made of atoms of low atomic number like $\mathrm{SiO}_{2}$.

2) the sample holder was polarized at $-9 \mathrm{~V}$, impeding the recollection of the emitted electrons and the sample current $I_{E}$ is measured over the whole energy range.

Knowing $I_{E}$ and $I_{0}$, the TEEY can be deduced using the following expression [3]:

$$
\text { TEEY }=\frac{I_{E}}{I_{0}}=\frac{I_{0}-I_{S}}{I_{0}} .
$$

The TEEY is a phenomenon that is mainly affected by the first few or tens nanometers beneath the surface [8]. The contamination layer that usually builds-up on the surface after air exposure, has therefore a dominant impact on the TEEY [12]. To minimize contamination, the samples were quickly introduced after adjusting the layer thickness into the vacuum chamber, ensuring in that way a minimum exposing time. An in-situ x-ray photoelectron spectroscopy (XPS) measurement indicated a negligible amount of C-residues for all studied samples.

\section{RESULTS}

\section{A. $\mathrm{SiO}_{2}$ thickness mapping}

Mapping of the measured $\mathrm{SiO}_{2}$ thickness is presented on Fig. 3. The thick black circle on the figure represents the edge of the 2 inches Si-wafer, with the horizontal line marking the notch. The map applies only for the measured zone. The obtained variation in the layer thickness is of only $4.0 \mathrm{~nm}$ with the lowest values measured near the edge. As mentioned earlier the TEEY measurements are performed in the central zone (radius of $14 \mathrm{~mm}$ ). For this part the observed disparity is of $1.3 \mathrm{~nm}$ approving for a very good homogeneity in the thickness of the oxide layer. Any measurement near the center would not suffer the edge effects. 


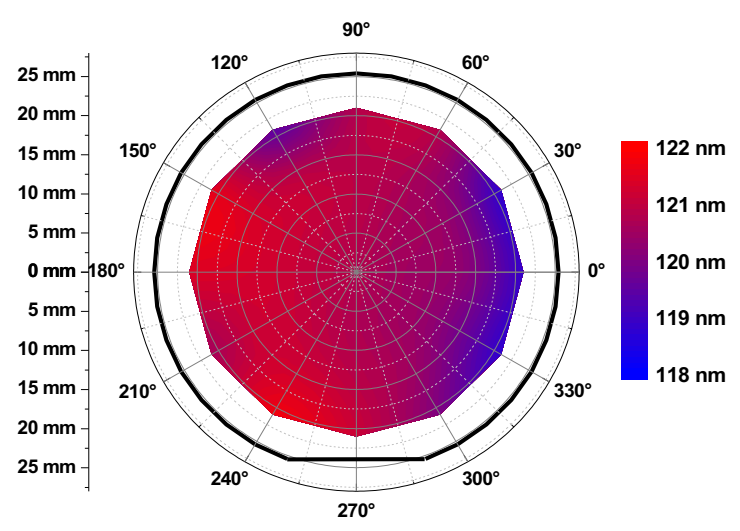

Fig. 3. Thickness map of thermal $\mathrm{SiO}_{2}$ thin layer over two inches Siwafer

\section{B. Fourier Transform Infra-Red spectroscopy}

The FTIR spectrum in Fig. 4 shows the characteristic absorbance peaks of $\mathrm{SiO}_{2}$, the three typical transversally-optic (TO) modes of molecular vibrations of amorphous silica: at $457 \mathrm{~cm}^{-1}$ attributed to $\mathrm{Si}-\mathrm{O}-\mathrm{Si}$ rocking, the symmetric stretching at $810 \mathrm{~cm}^{-1}$, the asymmetric stretching at $1085 \mathrm{~cm}^{-1}$ and the shoulder located at $1260 \mathrm{~cm}^{-1}$. The Full Width at Half Maximum (FWHM) of the asymmetric stretching $\mathrm{Si}-\mathrm{O}-\mathrm{Si}$ is quite narrow, only of $84 \mathrm{~cm}^{-1}$ which testifies for the wellorganized nature of the layer. One should also notice the absence of $\mathrm{C}$-related vibrations, like for example the symmetric stretching of $v_{\mathrm{g}}\left(\mathrm{CH}_{2}\right)$ at $2843 \mathrm{~cm}^{-1}$, the asymmetric stretching of $\mathrm{C}-\mathrm{H}$ in $\mathrm{CH}_{3}$ environment at $2960 \mathrm{~cm}^{-1}$, or of the stretching (free or associated) $\mathrm{O}-\mathrm{H}$ at $3450 \mathrm{~cm}^{-1}$ and $3630 \mathrm{~cm}^{-1}$, respectively. In terms of structural characterization, the choice of thermal $\mathrm{SiO}_{2}$ layers as model materials to study the required conditions to limit the dielectric charging phenomenon when measuring the electron emission yield from thin dielectric layers is well supported. It means that the interpretation of the obtained TEEY results cannot be attributed to contribution of structural disorder.

\section{TEEY measurements: pulse duration of the incident electron beam}

Fig. 5 shows a comparison between the TEEY spectra measured for continuous electrons-irradiation and pulsed irradiation (6 ms and $100 \mu$ s pulse duration) on a $90 \mathrm{~nm}$ -

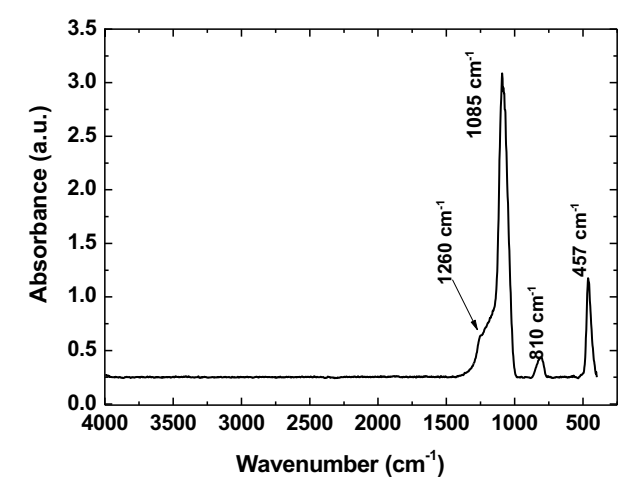

Fig. 4. FTIR spectrum of thermal $\mathrm{SiO}_{2}$ thin layer of $90 \mathrm{~nm}$ thickness thermal $\mathrm{SiO}_{2}$ layer proceeded on $\mathrm{Si}$ substrate (low doping level, type $n$ ). Under continuous electrons-irradiation beam the measured TEEY remains constant (about 1) over the whole explored range of the incident electron energy. This behavior is the obvious signature of charging effect. Indeed, according to the TEEY approach for dielectrics [7, 9, 13]: if TEEY is below 1 , a net negative charge is deposited in the sample. These charges give rise to an electric field in the vacuum of the specimen chamber, which slows the incident electrons and shifts their landing energy. This decrease of the landing energy leads to an increase of the total electron emission yield. The negative trapped charge reaches its saturation value of 1 . Conversely, if TEEY is over 1 the dielectric is charged positively, but very low energy secondary electrons are attracted back to the sample, the insulator is then charged to small positive potential (some Volts) and the TEEY falls quickly to 1 .

In order to limit the dielectric charging, short pulses electrons irradiation were used. When using a $6 \mathrm{~ms}$ pulse duration, the TEEY is higher at low energies and goes back to the saturated value of 1 from incident energies of $500 \mathrm{eV}$. The raise of TEEY for incident electron energies higher than $1500 \mathrm{eV}$ is not discussed in this paper. By shortening the pulse duration down to $100 \mu \mathrm{s}$, the yield does not get saturated, and higher values of TEEY are measured. An atypical TEEY response is obtained, with a dip located at $1000 \mathrm{eV}$. This atypical shape of the TEEY was already reported $[13,14]$. The phenomenon is currently under study and the mechanisms at play will be discussed in a forthcoming work. By shortening the incident electron pulse to $10 \mu$ s (not represented in Fig. 5), the TEEY remains the same, but the signal-noise ratio decreases which prevents from precise determination of the TEEY. Pulses duration between $10 \mu$ s and $100 \mu$ s appear to be well-adapted to measure the electron emission yield for $\mathrm{SiO}_{2}$ thin dielectrics. The optimal pulse duration may slightly vary according to the sample thickness and the incident electron density.

\section{TEEY measurements: hysteresis effect}

As described in section II.C, two steps are required to acquire the TEEY spectrum. For each step an energy scanning from low to high value is performed. As a consequence the first measurement of the second step (around $10 \mathrm{eV}$ energy) is following the last measurement of the first step (around $2 \mathrm{keV}$ ).

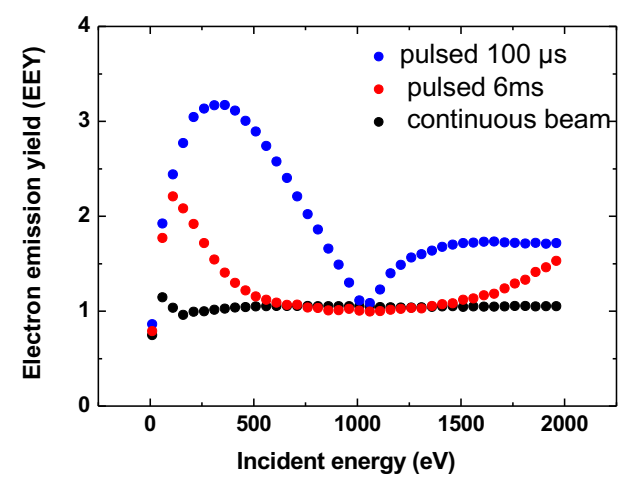

Fig. 5. Comparison of TEEY of a $90 \mathrm{~nm}$ thick $\mathrm{SiO}_{2}$ layer measured under continuous and pulsed electrons-irradiation beam. 
In order to study a possible hysteresis effect, TEEY measurements were performed considering thin (10 nm, Fig. 6) or thick (93 nm, Fig. 7) dielectrics. The incident energies were scanned from low to high value (labelled E increasing on Fig. 6 and 7) and from high value downwards (labelled E decreasing).

The Fig. 6 shows that the longer the incident pulse, the lower the TEEY is, in agreement with the results presented in section IV.C. The maximum yield is around $10 \%$ lower when using $6 \mathrm{~ms}$ pulses duration, compared to $10 \mu \mathrm{s}$ pulses. Moreover, the TEEY spectra obtained with ascending or descending incident electrons energy are close in the case of short pulses of $10 \mu \mathrm{s}$. For $6 \mathrm{~ms}$ pulses, the difference between the two spectra is not significant enough to conclude. In this case of thin $\mathrm{SiO}_{2}$ layer, the incident electrons can cross the layer, especially in the high energy range, and then the induced radiation induced conductivity is expected to release the stored charges. Also, as the capacitance is high relatively to the case of thicker layer, the expected voltage drop is less.

For the thicker $\mathrm{SiO}_{2}$, Fig. 7, layer the difference between TEEY spectra measured using increasing and decreasing incident energy is significant for $6 \mathrm{~ms}$. A drop of TEEY by up to $25 \%$ is measured in the case of scanning with decreasing E. This is probably linked to the positive charging of the material. When the TEEY is close to one, a low charge variation results, and therefore the charge state does not change. However, the deposited dose may lead to enhanced conductivity. We believe that the variation in TEEY is a combination of charging effects and irradiation. On the other hand, while using $100 \mu \mathrm{s}$

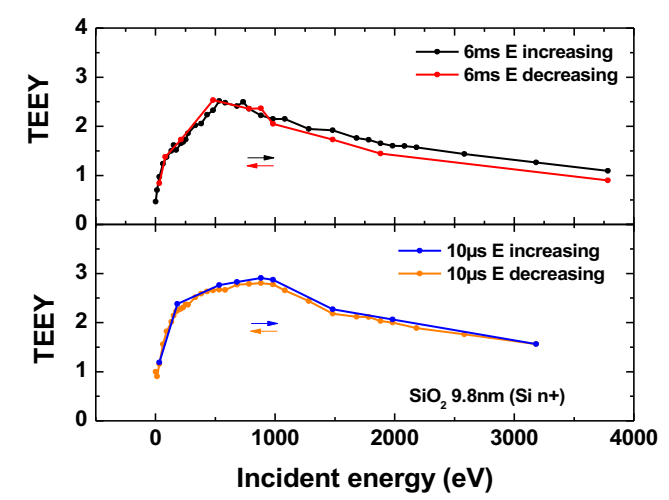

Fig. 6. TEEY of a $9.8 \mathrm{~nm}$ thick $\mathrm{SiO}_{2}$ layer, for $6 \mathrm{~ms}$ and $10 \mu$ s pulse duration.

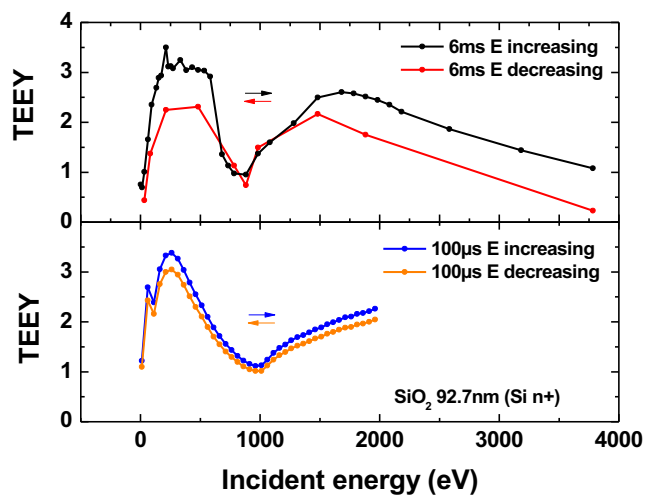

Fig. 7. TEEY of a $92.7 \mathrm{~nm}$ thick $\mathrm{SiO}_{2}$ layer, for $6 \mathrm{~ms}$ and $100 \mu$ s pulse duration. irradiation pulses, both curves are much closer, the maximum difference of TEEY being $6 \%$. With these short pulses we still distinguish a higher difference alongside the highest TEEY. Note that the peak observed at the very low energy range is an experimental artefact linked to electrostatic lenses of the electron gun and is therefore not characteristic of the material. The deep of TEEY at around $1 \mathrm{keV}$ is a competition between charge and discharge that will be discuss in further paper.

\section{CONCLUSION}

In this paper we showed that the pulse duration of the incident electrons beam has a great influence when measuring the TEEY for thin dielectric materials. In order to limit charges accumulation during measurements, pulses duration between $10 \mu \mathrm{s}$ and $100 \mu \mathrm{s}$ appear to be well-adapted. In the case of experimental conditions leading to charges accumulation within the sample (i.e. long pulse duration of $6 \mathrm{~ms}$ and thick sample of around $100 \mathrm{~nm}$ ), an hysteresis effect can be observed.

\section{REFERENCES}

[1] B. L. Thiel and M. Toth, "Secondary electron contrast in lowvacuum/environmental scanning electron microscopy of dielectrics," J. Appl. Phys., vol. 97, nº 5, p. 051101, 2005.

[2] R. Yu. P., Gas Discharge Physics, Berlin: Springer. 1991.

[3] N. Balcon, D. Payan, M. Belhaj, T. Tondu, and V. Inguimbert, "Secondary electron emission on space materials: Evaluation of the total secondary electron yield from surface potential measurements," IEEE Trans. Plasma Sci., vol. 40, $\mathrm{n}^{\circ}$ 2, pp. 282-290, 2012.

[4] A. Dunaevsky, Y. Raitses, and N. J. Fisch, "Secondary electron emission from dielectric materials of a Hall thruster with segmented electrodes," Phys. Plasmas, vol. 10, n ${ }^{\circ}$ 6, p. 2574-2577, 2003.

[5] K. Ohmi, "Beam-photoelectron interactions in positron storage rings," Phys. Rev. Lett., vol. 75, nº 8, p. 1526, 1995.

[6] M. Belhaj, "Contribution à l'étude de charge dans les isolants soumis à une irradiation électronique," PhD thesis, Université de Reims, 2001.

[7] J. Cazaux, "Some considerations on the secondary electron emission, $\delta$, from e- irradiated insulators," J. Appl. Phys., vol. 85, $\mathrm{n}^{\mathrm{o}} 2$, pp. 1137-1147, 1999.

[8] J. Cazaux, "Scenario for time evolution of insulator charging under various focused electron irradiations," J. Appl. Phys., vol. 95, $\mathrm{n}^{\circ} 2$, pp. $731-742,2004$.

[9] D. Joy, A database of electron-solid interactions, EM Facility, University of Tennessee, And Oak Ridge National Laboratory. 2008.

[10] J. Robertson, "High dielectric constant oxides," Eur. Phys. J. Appl. Phys., vol. 28, nº 3, pp. 265-291, 2004.

[11] D. A. G. Bruggeman, "Berechnung verschiedener physikalischer Konstanten von heterogenen Substanzen. I. Dielektrizit"atskonstanten und Leitf"ahigkeiten der Mischk"orper aus isotropen Substanzen," Ann. Phys., vol. 416, pp. 636-664, 1935.

[12] T. Gineste, M. Belhaj, G. Teyssedre, and J. Puech, "Investigation of the electron emission properties of silver: From exposed to ambient atmosphere Ag surface to ion-cleaned Ag surface," Appl. Surf. Sci., vol. 359, pp. 398-404, 2015.

[13] M. Belhaj and D. Payan, "About the electron emission properties of dielectric materials," Conf Mulcopim, Noordwijk The Netherlands, 2017, unpublished.

[14] K. Makasheva, M. Belhaj, G. Teyssedre, C. Rigoudy, S. Dadouch, and L. Boudou, "New insight in the secondary electron emission phenomenon when originating from very thin layers," Proc. IEEE Int. Conf. on Nanotechnology (IEEE NANO), vol. 1, pp. 515-516, 2017. 